\title{
Frontières
}

\section{VARIN, Claire, La Mort de Peter Pan, 2009, Montréal, Québec Amérique, $216 \mathrm{p}$.}

\section{Claude Cornillon-Richard}

Volume 21, numéro 2, printemps 2009

Détresse psychique et antidépresseurs

URI : https://id.erudit.org/iderudit/039468ar

DOI : https://doi.org/10.7202/039468ar

Aller au sommaire du numéro

\section{Éditeur(s)}

Université du Québec à Montréal

ISSN

1180-3479 (imprimé)

1916-0976 (numérique)

Découvrir la revue

Citer ce compte rendu

Cornillon-Richard, C. (2009). Compte rendu de [VARIN, Claire, La Mort de Peter Pan, 2009, Montréal, Québec Amérique, 216 p.] Frontières, 21(2), 89-89.

https://doi.org/10.7202/039468ar

Ce document est protégé par la loi sur le droit d'auteur. L'utilisation des services d'Érudit (y compris la reproduction) est assujettie à sa politique d'utilisation que vous pouvez consulter en ligne.

https://apropos.erudit.org/fr/usagers/politique-dutilisation/
Cet article est diffusé et préservé par Érudit.

Érudit est un consortium interuniversitaire sans but lucratif composé de l’Université de Montréal, l'Université Laval et l'Université du Québec à Montréal. Il a pour mission la promotion et la valorisation de la recherche. https://www.erudit.org/fr/ 


\section{VARIN, Claire}

\section{La Mort de Peter Pan}

2009, Montréal, Québec Amérique, $216 \mathrm{p}$.

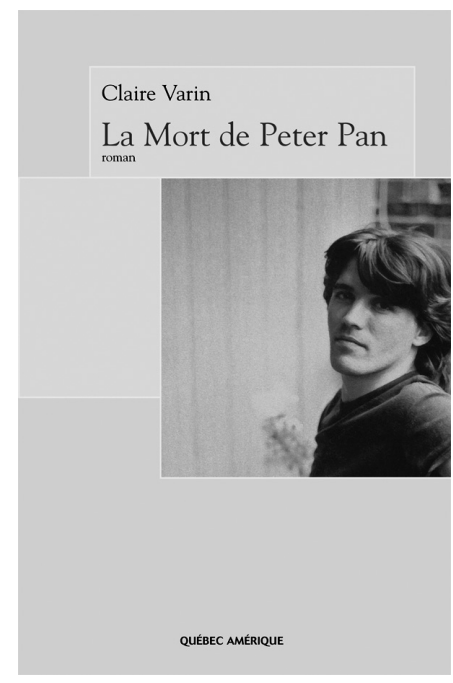

Ce roman évoque I'histoire d'une relation que la narratrice a entretenue avec Malcolm Wendell Walker dont elle a été amoureuse et qui est décédé dans un incendie à l'âge de 30 ans.

Tout au long du roman, elle reconstitue pour nous le personnage de Walker en évoquant des bribes de leur histoire d'amour. Pour ce faire, elle reprend contact avec la mère de celui-ci, avec ses amoureuses et ses amis. Walker a eu une enfance troublée. Placé dans une crèche, puis dans un orphelinat, un foyer d'accueil et une école de réforme, il retourne finalement vivre avec sa mère quand celle-ci voit sa situation financière s'améliorer. Mais, le développement affectif et émotionnel de Walker est resté bloqué au stade de l'adolescence. II présente tous les traits psychologiques du syndrome de Peter Pan. En effet, il manifeste son immaturité en recherchant avec sa partenaire une relation proche de celle $d^{\prime}$ 'une mère avec son enfant - un amour inconditionnel qu'il ne cesse de tester en mettant la narratrice à l'épreuve. De plus, son angoisse face au monde extérieur et son incapacité à se situer dans la réalité de ce monde l'amènent à sombrer dans la boisson, jusqu'au jour où il s'endort avec une cigarette allumée à la main.

Tout au long des neuf mois qu'a duré leur histoire d'amour, la narratrice semble fascinée par le magnétisme de cet homme. On peut se demander ce qui suscite cet envoûtement. Et si elle avoue avoir été amoureuse de Walker, elle ne semble pas s'être véritablement engagée dans une relation avec lui. Est-ce la brièveté des chapitres qui ne nous permet pas de rejoindre les émotions ou bien est-ce le fait que la narratrice a de la difficulté, après toutes ces années, à renouer avec ses sentiments pour lui ? Ce roman qui aborde le thème de la mort aurait pu être un roman sur le deuil mais il est surtout un dialogue avec le souvenir de l'amant décédé, une enquête à la recherche d'un fantôme.

\section{Claude Cornillon-Richard}

\section{DIDION, Joan \\ L'année de la pensée magique}

2007, Paris, Grasset, 281 p.



Joan Didion est une figure intellectuelle marquante des lettres américaines contemporaines. Devenue une chroniqueuse très appréciée de la scène politique et culturelle américaine, elle contribue régulièrement aux magazines The New Yorker et The New York Review of Books.

Dans L'année de la pensée magique, ouvrage couronné par le National Book Award, Joan Didion raconte la mort de son mari et sa première année de deuil. C'est par une soirée ordinaire, fin décembre 2003, que John Gregory Dunne s'écroule sur la table de la salle à manger, victime d'une crise cardiaque foudroyante. Ajoutons que ce décès subit intervient six jours seulement après que leur fille unique ait été hospitalisée en urgence, et alors qu'elle se trouve encore entre la vie et la mort. Pendant une année entière, Didion essaiera de se résoudre à la mort de son compagnon, tout en s'occupant de leur fille, plongée dans le coma.

Le récit commence avec ces mots: "La vie change vite. " "La vie change dans l'instant. " "On s'apprête à dîner et la vie telle qu'on la connaît s'arrête. » Didion souligne la banalité de l'instant « ordinaire » où le drame se produit: un jour comme les autres alors que la mort d'un être cher, l'impensable, se produit. L'auteure aborde l'incrédulité, l'incompréhension et la souffrance qui entourent cet événement si commun et si inconcevable à la fois. Didion va nous faire part de son cheminement dans le deuil: sa manière de refuser la mort de son mari, de chercher à la comprendre puis de l'apprivoiser petit à petit grâce à la lecture et à l'écriture pour enfin reconnaître que «si nous voulons vivre nous-mêmes, vient un moment où nous devons nous défaire de nos morts, les laisser partir, les laisser morts".

Mais l'auteure ne parviendra à ce constat qu'après avoir refusé la mort de John. Le faire revenir était son seul objectif pendant L'année de la pensée magique, celle où elle aura cru que ses pensées ou sa volonté avaient la force de renverser le cours de l'histoire, d'en changer l'issue. Elle considère qu'il ne faut pas «laisser d'autres personnes penser que John est mort » et elle en vient ainsi à vivre dans un monde tout à fait irrationnel. En effet, si elle autorise l'autopsie c'est pour examiner ce qui ne va pas chez John et pouvoir peut-être le réparer, si elle refuse une nécrologie, c'est parce qu'elle craint de I'enterrer vivant, d'accepter une mort définitive ou de l'empêcher de revenir, si elle refuse de donner ses chaussures c'est parce qu'il doit les trouver à son retour, si elle refuse le don d'organes c'est parce qu'il va en avoir besoin. Et I'on ne peut qu'admirer la ténacité de Didion à vouloir mettre des mots sur des croyances et des sentiments tellement déraisonnables, à vouloir faire face à la dérive de sa pensée rationnelle. Rappelons que, pour Didion, mettre des mots était la seule façon de comprendre, de mettre de l'ordre dans le chaos qu'elle vivait, de retrouver une certaine cohérence.

Pour commencer, Didion se concentre sur la mort elle-même en tentant une reconstitution minutieuse des événements et en prenant connaissance du rapport d'autopsie car il lui fallait croire pour de bon à la mort de John. C'est grâce à ce travail qu'elle va se rendre à l'évidence: la mort de John était pré- visible puisqu'il avait déjà subi une chirurgie cardiaque, et d'ailleurs lui-même se considérait en sursis. Elle va enfin admettre qu'elle était totalement impuissante et qu'elle n'aurait pas pu changer les choses alors que, jusque-là, elle se sentait coupable de n'avoir pu le sauver ni le ramener à la vie.

Par ailleurs, Didion veut lire, apprendre, se référer à des textes, puisqu'on lui avait enseigné que savoir c'est contrôler. C'est pourquoi, elle va aller chercher des réponses sur la mort et le deuil dans des manuels de psychanalyse et de médecine, ainsi que chez les auteurs, les poètes et les philosophes qui ont abordé ces sujets.

Didion ne s'abandonne pas au désespoir, ne se replie pas sur ellemême, mais trouve dans le souvenir de la vie passée la force de continuer. Au passage, elle mentionne sa vie riche et variée avec son mari, elle, auteure et journaliste, lui, scénariste de films, et nous fait part de la confiance mutuelle qu'ils éprouvaient I'un pour l'autre. On les suit lors des tournages, on les accompagne dans leurs voyages et on ressent leur complicité.

Un livre très intéressant où I'auteure ne s'apitoie jamais sur elle-même, où elle raconte ce qu'elle ressent, sobrement et sans pathos, démonte les mécanismes du deuil et souligne la difficulté de reprendre la vie après la perte de l'être cher. C'est un récit très précis, presque clinique et très pudique, écrit dans un style retenu, mais où transparaissent l'émotion, la déstabilisation, la douleur du manque et la conscience de l'absence.

Shahira El Moutei-Khalil 